\title{
Análise do efeito da camuflagem no tempo de segregação em regiões texturizadas utilizando o modelo de riscos proporcionais de Cox
}

\section{Analysis of the camouflage effect in time of segregation in texturized regions using the Cox proportional hazard model}

\author{
Eduardo Yoshio Nakano; ; Juliana Ferrari Cunha²
}

\section{Resumo}

Os seres humanos possuem visão tricromática. No entanto, variações nos genes podem provocar deficiências na visão em cores levando ao dicromatismo. O objetivo deste trabalho foi verificar a real eficiência dos dicromatas na quebra de camuflagem por cor. Participaram desse estudo nove indivíduos daltônicos e a resposta foi o tempo de segregação de alvos camuflados. O interesse foi comparar o tempo de resposta em várias condições de camuflagem e a análise dos dados foi realizada utilizando o modelo de riscos proporcionais de Cox.

Palavras-chave: Discromatopsia. Camuflagem. Análise de Sobrevivência. Riscos Proporcionais.

\begin{abstract}
Humans have trichromatic vision. However variations in gene can cause deficiency in color vision resulting to dichromatism. The aim of this work was to verify the real efficiency of dichromats to break colour camouflage. Total of nine colour-blind individuals participated in this study and the variable considered was the time to segregation of camouflaged targets. The interest was to compare the response time in several conditions of camouflage and the analysis was performed using the Cox proportional hazard model.
\end{abstract}

Key words: Dyschromatopsia. Camouflage. Survival analysis. Proportional hazards.

\footnotetext{
${ }^{1}$ Departamento de Estatística, Universidade de Brasília-UnB; nakano@unb.br.

2 Departamento de Biologia, Universidade de Brasília-UnB; juferrari@unb.br.
} 


\section{Introdução}

O processo biológico que resulta na visão em cores é iniciado pela comparação neural de sinais provenientes de diferentes classes de foto-receptores (JACOBS, 1996; KANDEL; SCHWARTZ; JESSEL, 2003). A existência de uma, duas ou três classes de foto-receptores confere a um indivíduo a condição monocromática, dicromática ou tricromática, respectivamente.

Enquanto a maioria dos mamíferos apresenta visão em cores dicromática, os seres humanos possuem visão tricromática. Mas variações nos genes podem provocar "deficiências" da visão em cores levando ao dicromatismo.

Segundo Pokorny et al. (1979) na população caucasiana, $8 \%$ dos homens apresentam deficiência para a visão de cores no eixo verdevermelho (indivíduos daltônicos). Esta incidência do daltonismo sugere que possa existir alguma vantagem compensatória nessa forma de visão. Durante a Segunda Guerra Mundial, foi sugerido que os observadores daltônicos conseguiam detectar alvos camuflados que não eram percebidos por tricromatas normais (ANON, 1940; JUDD, 1943). Essa ideia foi aplicada para a camuflagem militar (REIT, 1979) e para a camuflagem no ambiente natural (KALMUS, 1965). Posteriormente, Morgan, Adam e Mollon (1992), usando um protocolo experimental controlado, demonstraram que indivíduos dicromatas podem detectar regiões texturizadas por orientação mesmo que estas estejam em meio a uma organização perceptual rival, a variação aleatória de cores no eixo vermelho-verde.

Neste contexto, o objetivo deste trabalho foi verificar a real eficiência dos dicromatas na quebra de camuflagem por cor. Para tanto foram analisados os tempos de resposta de indivíduos dicromatas na segregação de alvos camuflados. A técnica de Análise de Sobrevivência foi utilizada para a análise dos tempos de respostas até a segregação. A necessidade do uso das técnicas de Análise de Sobrevivência se deve ao fato dos dados (tempo em segundos até a segregação do alvo) apresentarem censuras. Neste trabalho, a censura ocorre quando o indivíduo erra o alvo ou quando o mesmo não identifica o alvo no tempo estabelecido. O interesse da análise foi a comparação do tempo de segregação dos alvos camuflados e não camuflados para indivíduos dicromatas através de estimativas e comparações da curva de sobrevivência, da função de risco e do tempo médio de segregação.

As curvas de sobrevivências foram obtidas pelo estimador não-paramétrico de Kaplan-Meier (KAPLAN; MEIER, 1958) e suas comparações foram realizadas através do teste de Log-Rank (CARVALHO et al., 2005). Ademais, foi realizado um estudo do modelo de Riscos Proporcionais de Cox (COX, 1972), verificando um possível ajuste do modelo para o conjunto de dados. O modelo de Cox se mostrou adequado para comparar os tempos de segregação dos alvos camuflados e não camuflados nas diferentes situações de camuflagem. A contribuição do modelo de Cox neste trabalho se deve na facilidade da verificação de uma hipótese de proporcionalidade dos riscos que, quando verdadeira, permite uma melhor interpretação dos resultados e possibilita a estimação dos riscos relativos.

\section{Metodologia}

\section{Descrição do experimento}

Participaram do trabalho nove indivíduos daltônicos, todos do sexo masculino e com discromatopsias no eixo vermelho-verde. Nenhum sujeito apresentou discromatopsia no eixo azulamarelo. Os indivíduos foram esclarecidos quanto aos procedimentos da pesquisa. Após o esclarecimento, eles decidiam se queriam ou não participar. Os que participaram assinaram o termo de consentimento livre e esclarecido obedecendo aos critérios do Comitê de Ética em Pesquisa da Faculdade de Ciências da Saúde (CEP/FS) da Universidade de Brasília. 
Para a realização dos testes foi elaborado um programa de computador na linguagem Java (versão jbk 1.4) pelos analistas de sistemas Denis e José Marcos Barbosa da Silveira. O programa foi chamado de Sistema de Camuflagem. Este programa gera condições artificiais, de camuflagem por cor.

A tela do computador estava preenchida por minúsculos retângulos coloridos na posição vertical. Em alguma parte deste cenário, os retângulos apareciam na posição horizontal (veja Figura 1). Os retângulos na horizontal representavam o alvo que os sujeitos tinham que encontrar. O restante representava o fundo do estímulo. Essa estruturação foi baseada em um experimento anterior conduzido por Morgan, Adam e Mollon (1992).

A tela foi dividida em quatro quadrantes, porém não aparecia linha divisória entre os quadrantes. Embora a ordem das aparições fosse aleatória, para evitar que o alvo aparecesse mais vezes no meio da tela do que nas extremidades, situação que poderia comprometer os dados, as aparições foram balanceadas (pseudo-aleatórias). Ou seja, de acordo com as coordenadas (x,y), o número de vezes em que alvo surgia nos cantos extremos, numa posição intermediária e bem no meio da tela era aproximadamente igual.

A tela de estímulos poderia estar nas situações camuflada por cor ou não-camuflada (Figura 1). Na situação de camuflagem, os elementos do estímulo eram aleatoriamente coloridos formando um mosaico de cores. Apenas duas cores, além do fundo que era cinza, formavam o mosaico. Porém, dois tipos de mosaicos poderiam aparecer nos testes: o mosaico vermelho-verde, denominado de Mosaico 1 (M1); e o mosaico azul-amarelo, denominado de Mosaico 2 (M2). Na situação sem camuflagem, ou situação controle, todos os elementos eram de uma mesma cor, podendo ser ou vermelho (ou laranja), ou verde, ou azul, ou amarelo. As cores na situação sem camuflagem foram denominadas cores homogêneas ou sólidas (S).
Os sujeitos se encontravam a uma distância de $57 \mathrm{~cm}$ da tela. A posição da cabeça era fixada por um aparelho estereotáxico. Não foi pedido que os sujeitos fixassem o olhar em qualquer ponto da tela, pois o objetivo era que eles explorassem visualmente a cena. $\mathrm{O}$ ambiente encontrava-se iluminado por uma lâmpada de iluminante D-65.

Figura 1 - Estímulo nas situações não-camuflada (A) e camuflada (B). As setas na imagem indicam o alvo. O tamanho dos elementos da figura não corresponde ao original.
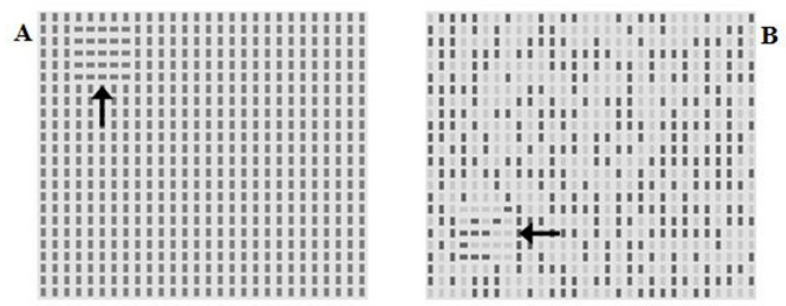

Fonte: Cunha (2005)

Para cada indivíduo, o teste apresentava 48 telas de estímulos. Dessas 48 telas, 16 eram de cores sólidas (quatro vermelhas, quatro verdes, quatro azuis e quatro amarelas), 16 eram de mosaico vermelho-verde e 16 eram de mosaico azulamarelo. Cada situação, cores sólidas ou mosaicos, aparecia quatro vezes em cada quadrante e a ordem das aparições das diferentes situações era aleatória.

Antes da apresentação de cada tela de estímulo, aparecia um "+" no centro da tela (Figura 2). O objetivo do "+" era que a posição do mouse estivesse equidistante em relação aos quadrantes. O sujeito deveria clicar nesse "+" para que a tela de estímulos aparecesse. A tela ficava acesa um determinado tempo para que o sujeito encontrasse o alvo. O objetivo era encontrar o alvo e clicar em cima dele. Quando a tarefa era cumprida, a tela de estímulos era trocada novamente pela tela com o "+". Dessa forma recomeçava uma nova tentativa, até que todas as tentativas fossem completadas. 
Figura 2 - Ordem de aparição do estímulo. Primeiramente surge uma tela com um "+" no centro (A) para depois entrar na tela de estímulo (B).

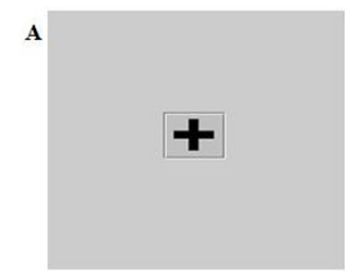

Fonte: Cunha (2005)

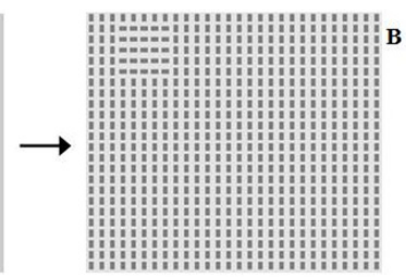

Se, por acaso, o sujeito não encontrasse o alvo no tempo estabelecido ou se ele clicasse em um local errado, a tentativa era descartada e considerada como se o sujeito não tivesse visto o alvo (dado censurado). O tempo de aparição da tela de estímulo foi determinado de acordo com o desempenho de cada sujeito em sessões de treinamento. O treinamento era muito semelhante aos testes, porém todas as telas de estímulos eram de cores homogêneas. O sujeito treinava até que tivessem entendido a tarefa. $\mathrm{O}$ tempo médio que o sujeito levou para encontrar o alvo nas sessões de treinamento era somado ao seu desviopadrão para fornecer o tempo de apresentação do estímulo nos testes. O desvio-padrão foi acrescentado para que houvesse uma margem de erro não-aleatória do tempo. Se fosse estabelecido, por exemplo, um acréscimo fixo de um segundo para cada sujeito, talvez esse tempo fosse demais para alguns e de menos para outros.

\section{Metodologia Estatística}

Os dados do tempo de segregação dos alvos foram analisados por meio de técnicas de Análise de Sobrevivência, onde T é a variável que denota o tempo (em segundos) que o indivíduo levou para encontrar o alvo.

O procedimento adotado nesse protocolo caracteriza o uso de censuras à direita dos tipos I e aleatória. $\mathrm{O}$ evento de interesse foi a segregação do alvo e a observação foi censurada quando o indivíduo não encontrou o alvo no tempo pré-estabelecido (censura do tipo I), ou quando ele clicou em um local que não era o alvo (censura aleatória). Para mais detalhes sobre os diferentes mecanismos de censura, veja Carvalho et al. (2005). Esse protocolo previu um tempo pré-estabelecido de aparição do alvo pois em seu estudo original, Cunha (2005) comparou os grupos através da frequência e percentual de segregação dos alvos sem considerar o seu tempo.

Este estudo foi realizado através da análise das curvas de sobrevivência e da função de risco. As curvas de sobrevivência foram obtidas através do estimador não-paramétrico de Kaplan-Meier (KAPLAN; MEIER, 1958).

O teste utilizado para a comparação das três curvas de sobrevivência foi o de Log-Rank (CARVALHO et al., 2005). A comparação entre-grupos foi realizada através do teste de Log-Rank comparando as curvas de sobrevivência duas-a-duas e ajustando o nível de significância pela correção de Bonferroni. Ademais, foi ajustado um modelo de Riscos Proporcionais de Cox (COX, 1972), considerando uma única covariável categórica com três níveis identificando os grupos S, M1 e M2. O modelo de Cox foi utilizado para comparar os três estímulos e estimar o risco relativo (risco do indivíduo segregar o alvo) considerando a situação de não camuflagem (grupo S) como nível de referência.

A análise de resíduos escalonados de Schoenfeld (CARVALHO et al., 2005) foi utilizada para verificar a suposição dos riscos serem proporcionais. A proporcionalidade dos riscos é importante pois permite uma interpretação "independente" do tempo. Se a suposição de riscos proporcionais for rejeitada, os riscos relativos podem ser estimados e os mesmos permanecem constantes ao longo do tempo. Assim, ao se mensurar o quanto os riscos de segregação nos Mosaicos são maiores (ou menores) que na situação de cor sólida, grandeza é constante ao longo do tempo.

Os dados foram analisados utilizando os comandos da biblioteca survival do software R ( R Development Core Team, 2011). Todos os testes 
foram realizados assumindo hipóteses bilaterais e um nível de significância de 5\%.

\section{Resultados e discussões}

Em consonância com os objetivos propostos, dada a obtenção dos resultados conforme a realização do experimento descrito na Seção 3.1, os resultados são apresentados nas Tabelas 1 e 2.

Tabela 1 - Estatísticas do tempo de segregação e teste Log-Rank.

\begin{tabular}{lccccc}
\hline Cor & $\mathrm{n}$ & Média (IC 95\%) & \multicolumn{3}{c}{ Teste Log-Rank } \\
& [censuras] & {$[$ mediana $]$} & $\mathrm{X}^{2}$ & $\mathrm{gl}$ & $\mathrm{p}$ \\
\hline $\mathrm{S}$ & 144 & $3,04(2,77-3,31)$ & & & \\
& {$[8]$} & {$[2,46]$} & & & \\
\cline { 1 - 3 } M1 & 144 & $2,97(2,70-3,24)$ & 25,2 & 2 & $<0,001^{*}$ \\
& {$[7]$} & {$[2,42]$} & & & \\
\hline M2 & 144 & $4,01(3,66-4,36)$ & & & \\
& {$[32]$} & {$[3,41]$} & & & \\
\hline
\end{tabular}

* $\mathrm{S}=\mathrm{M} 1 ; \mathrm{S} \neq \mathrm{M} 2 ; \mathrm{M} 1 \neq \mathrm{M} 2$. Resultados obtidos considerando um nível de significância de 5\%. Nível de significância ajustado pela correção de Bonferroni.

Fonte: Os autores

Pode-se notar pelo teste de Log-Rank, que existe diferença nas funções de sobrevivência entre as diferentes situações de camuflagem $(p<0,001)$. Os tempos médios de segregação do alvo entre as situações de cores sólidas e do Mosaico 1 não diferiram significativamente, indicando que os indivíduos daltônicos não levaram mais tempo para identificar o alvo no Mosaico 1, quando comparado com a situação de cor sólida. Já no Mosaico 2, esses indivíduos apresentaram um tempo de segregação maior que no Mosaico 1 e que na situação de cor sólida. A função de risco acumulado apresentada na Figura 3 mostra que o risco de segregação do alvo no Mosaico 2 é menor que nas outras situações, ou seja, os indivíduos daltônicos levam mais tempo para identificar o alvo no Mosaico 2.
Tabela 2 - Ajuste do modelo de riscos proporcionais de Cox para as diversas situações de camuflagem.

\begin{tabular}{lcccc}
\hline Cor & Coef. & $\begin{array}{c}\text { Risco Relativo } \\
\text { (IC 95\%) }\end{array}$ & $\mathrm{z}$ & $\mathrm{p}$ \\
\hline M1 & 0,045 & 1,046 & 0,373 & 0,710 \\
& & $(0,83-1,33)$ & & \\
M2 & $-0,534$ & 0,586 & $-4,177$ & $<0,001$ \\
& & $(0,46-0,75)$ & & \\
\hline
\end{tabular}

A situação de não camuflagem (cores sólidas) é o nível de referência.

Fonte: Os autores

Observando os resultados da Tabela 2, o único coeficiente significativo foi o do Mosaico 2. Assim, segundo o modelo de Cox, o risco de segregação do alvo em uma situação de camuflagem no mosaico azul-amarelo é 0,586 vezes $(41,4 \%$ menor) o risco da segregação do alvo em uma situação de cor homogênea (sem camuflagem). Como o coeficiente do Mosaico 1 não foi significativo ( $\mathrm{p}=0,710)$, não há diferença significativa entre o risco de segregação do alvo entre a situação de cor sólida e o Mosaico 1.

Figura 3 - Estimativas das funções de sobrevivência e risco acumulado para o tempo de segregação do alvo em diferentes situações de camuflagens, obtidas pelo estimador de Kaplan-Meier

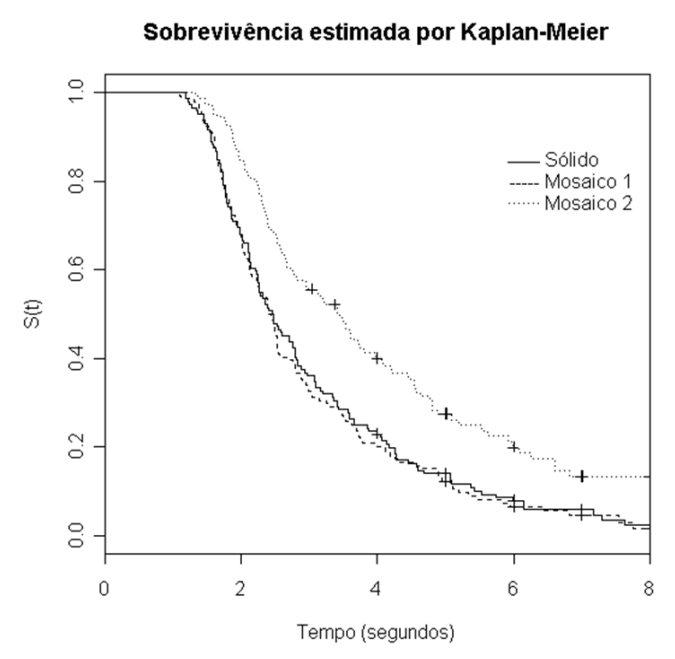




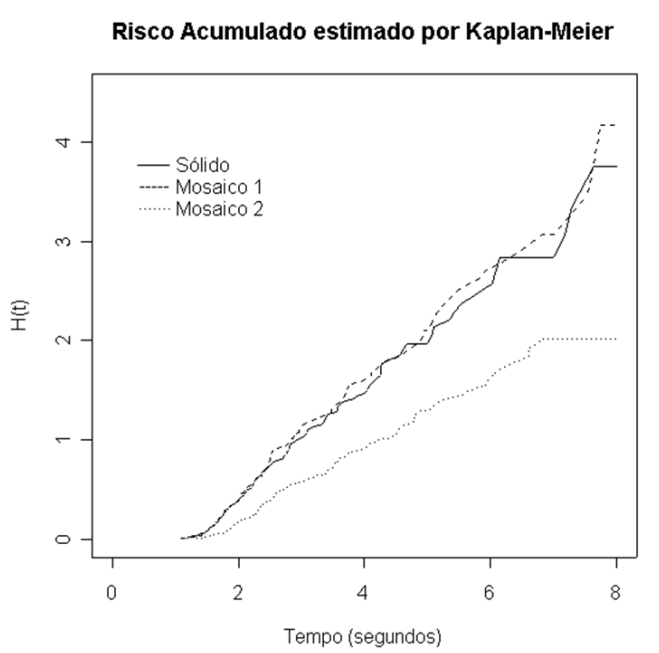

Fonte: Os autores

A Figura 4 apresenta as estimativas das funções de sobrevivência e risco segundo o modelo de Riscos Proporcionais de Cox.

Figura 4 - Estimativas das funções de sobrevivência e risco para o tempo de segregação do alvo em diferentes situações de camuflagens, obtidas pelo modelo de Riscos Proporcionais de Cox.

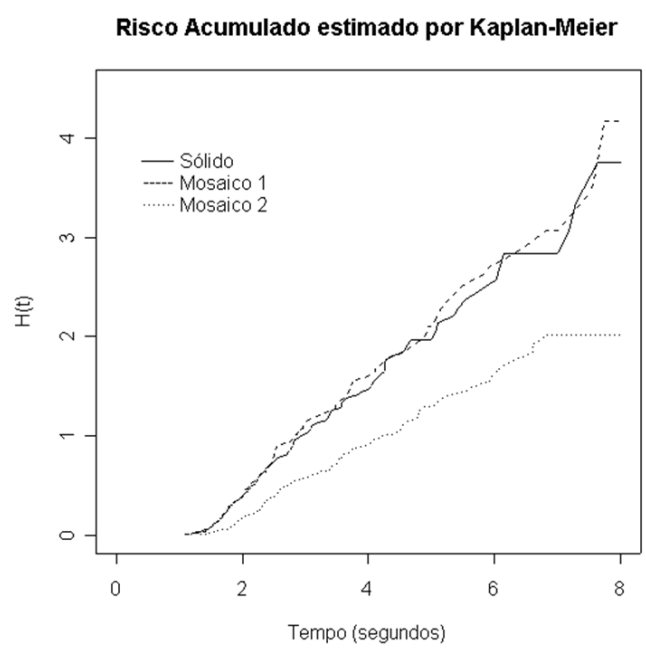

Risco Acumulado Estimado pelo Modelo de Cox

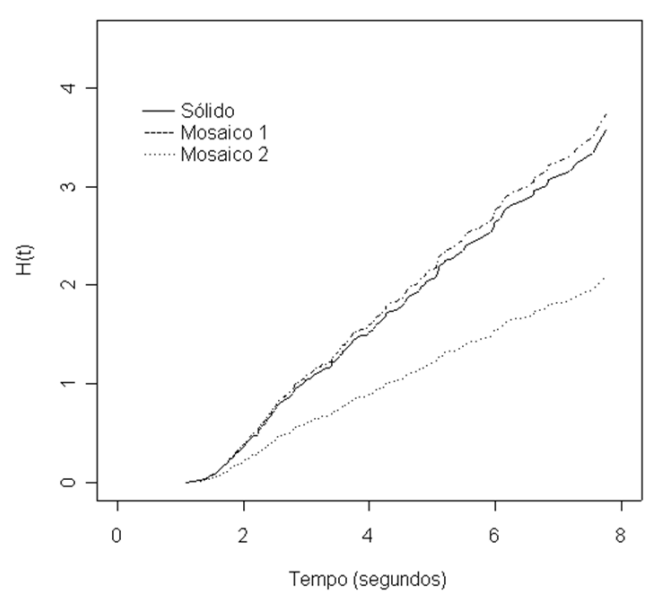

Fonte: Os autores

Para verificar se o ajuste do modelo de Cox é adequado aos dados sob estudo, serão utilizados os resíduos escalonados de Schoenfeld (CARVALHO et al., 2005). Os resultados são apresentados na Tabela 3 e Figura 5.

Tabela 3 - Teste de tendências.

\begin{tabular}{lccc}
\hline & rho & $\mathrm{X}^{2}$ & p-valor \\
\hline Mosaico 1 & 0,0029 & 0,0032 & 0,955 \\
Mosaico 2 & 0,0721 & 1,9668 & 0,161 \\
GLOBAL & NA & 2,4451 & 0,294 \\
\hline
\end{tabular}

A situação de não camuflagem (cores sólidas) é o nível de referência.

Fonte: Os autores

Pode-se observar que não há tendências significativas tanto para a situação do Mosaico 1 quanto para o Mosaico 2 ( $\mathrm{p}=0,955$ e $\mathrm{p}=0,161$, respectivamente). Nos gráficos apresentados pela Figura 5 é possível visualizar tais tendências não acentuadas ao longo do tempo. Desta forma, a suposição de riscos proporcionais não está sendo violada na análise desses dados. 
Figura 5 - Resíduos escalonados de Schoenfeld.
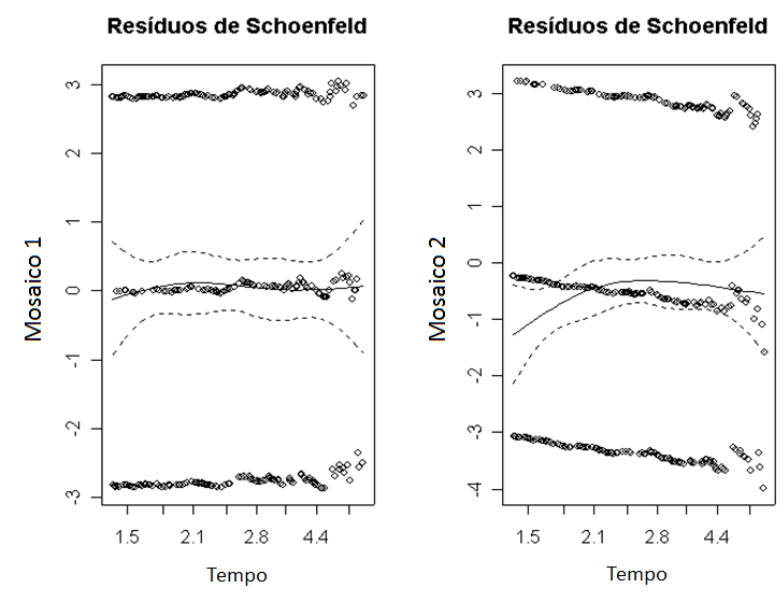

Fonte: Os autores

\section{Conclusões}

Face aos resultados observados pode-se concluir que, entre os indivíduos daltônicos, existe diferença entre os tempos de segregação em diferentes situações de camuflagem por cor. O tempo de segregação do alvo em uma situação de cor sólida é o mesmo que na situação de Mosaico 1 (verdevermelho). Isso se deve ao fato dos indivíduos daltônicos apresentarem uma deficiência para a visão de cores no eixo verde-vermelho, fazendo com que ele quebre a camuflagem do Mosaico 1. Pode-se notar que isso não ocorre no Mosaico 2 (azul-amarelo), porque os mesmos são capazes de diferenciar as cores azul e amarelo, caracterizando assim uma situação de camuflagem.

Os resultados desse trabalho estão de acordo com experimentos anteriores (MORGAN; ADAM; MOLLON, 1992) que sugerem que os indivíduos daltônicos possam ter vantagem sobre os tricromatas normais em penetrar camuflagem por cor se esta se encontra no eixo vermelho-verde. Os indivíduos daltônicos não percebem, ou percebem fracamente, o ruído acrescentado à cena quando esta contém elementos aleatoriamente coloridos por tons no eixo vermelho-verde. Com base nisso, pode-se dizer que em uma cena visual complexa, onde a cor dos componentes varia no eixo de confusão dos daltônicos, esses indivíduos irão captar mais rapidamente que os indivíduos normais os outros atributos visuais da cena sejam estes forma, movimento ou brilho.

\section{Agradecimentos}

Os autores agradecem os analistas de sistemas Denis e José Marcos Barbosa da Silveira por elaborarem o programa Sistema de Camuflagem utilizado neste estudo. A segunda autora agradece a Coordenação de Aperfeiçoamento de Pessoal de Nível Superior (CAPES) pelo apoio financeiro concedido para o desenvolvimento deste trabalho

\section{Referências}

ANON. Colour-blindness and camouflage. Nature, London, v. 146, p. 226, Aug. 1940.

CARVALHO, M. S.; ANDREOZZI, V. L.; CODEÇO, C. T.; BARBOSA, M. T. S.; SHIKAMURA, S. E. Análise de Sobrevida: teoria e aplicações em Saúde. Rio de Janeiro: Fiocruz, 2005.

COX, D. R. Regression models and life tables (with discussions). Journal of the Royal Statistical Society. Series B, London, v. 34, n. 2, p. 187-202, 1972.

CUNHA, J. F. Segregação de texturas camufladas por cor em indivíduos dicromatas e tricromatas. 2005. Dissertação (Mestrado em Biologia) - Departamento de Biologia Animal, Universidade de Brasília, Brasília.

JACOBS, G. H. Primate photopigments and primate color vision. Proceedings of the National Academy of Sciences of the United States of America, Washington, v. 93, p. 577-581, 1996.

JUDD, D. B. Colour blindness and the detection of camouflage. Science, Washington, v. 97, p. 544-546, 1943.

KALMUS, H. Diagnosis and genetics of deflective colour vision. Oxford: Pergamon Press, 1965.

KANDEL, E. K; SCHWARTZ, J. K.; JESSEL, T. M. Principios da Neurociência. São Paulo: Manole, 2003.

KAPLAN, E. L.; MEIER, P. Nonparametric estimation from incomplete observations. Journal of the American Statistical Association, New York, v. 53, p. 457-481, 1958. 
MORGAN, M. J; ADAM, A.; MOLLON, J. D. Dichromats detect colour-camouflaged objects that are not detected by trichromats. Proceedings: Biological sciences, London, v. 248, n. 1323, p. 291-295, 1992.

POKORNY, J.; SMITH, V. C.; VARRIEST, G.; PINCKERS, A. J. L. G. Congenital and acquired color defects. New York: Grune \& Stratton, 1979.

R DEVELOPMENT CORE TEAM. R: A language and environment for statistical computing. Vienna, Austria. 2011. The R project for statistical computing. Disponível em: <http://www.R-project.org>. Acesso em: 20 mai. 2012.

REIT, S. Masquerade: the amazing camouflage deceptions of World War II. London: Robert Hale, 1979.

Recebido em 19 Outubro 2011-Received on October 19, 2011.

Aceito em 23 Maio, 2012 - Accepted on May 23, 2012. 